\title{
AUTOMATED IMAGE PREPARATION FOR CONTOUR CONTRAST REPRODUCTION CONTROL
}

\author{
Irina Artyushina, Aleksey Vinokour, Aleksey Glazkov \\ Moscow Polytechnic University, Russia \\ i.1.artyushina@mospolytech.ru, a.i.vinokur@mospolytech.ru, alexglazkov889@gmail.com
}

\begin{abstract}
In the article the process of automated image preparation for multimedia reproduction is discussed. In general, the original and the copy have different dynamic ranges due to the technical properties of the particular visualization system. The problem of reproduction of contours with contrast close to the threshold of distinction is investigated. It is noted that there may appear two types of distortion of information, when reproducing with a change in the dynamic range of the image: in the copy the contours may appear, which are missing in the original and, conversely, the contours present in the original may disappear in the copy. The concept of contour contrast is introduced, on the basis of which the algorithm of automated image processing is proposed. The algorithm ensures contrast preservation of contours close to the threshold of perception, which allows accurate reproduction of contour information. The program implementation of the proposed algorithm is performed. Experimental testing confirms the efficiency of the approach.
\end{abstract}

Key words: image reproduction, contour, contrast.

\section{Introduction}

In modern practice of land cadastral or ecological interpretation of aerospace images visualization is made with the use of different technical systems [1]. The difference between one image and another is manifested, generally, in differences between reproductive coverages and the conditions of consideration. Reproduction coverage is characterized by resolution, dynamic range and color saturation. The conditions of consideration are characterized by the visual system adaptation to lighting, as well as the angle and scale of demonstration of the copy. These aspects should be taken into account to ensure the desired interpretation accuracy.

In this article only one aspect essential for interpretation is discussed: that is the transmission of contour information. As it is known [2;3], reproduction of contour information is the most important indicator of visualization quality.

In the process of preparing an aerial photo for visualization, a number of transformations are carried out, the purpose of which is to ensure the quality of object recognition with the help of the selected visualization system different in its capabilities from the one in which the original was created. This solves the multi-criteria optimization problem, the criteria of which are not explicitly formulated or even cannot be formulated. Typically, the set of solutions is Pareto-optimal, i.e., improving one characteristic, we worsen the other. For interpretation, it is necessary to find a compromise that meets the goals set. In any case, one of the most important criteria is the accuracy of contour information reproduction. The complexity of the problem lies in the fact that the preservation of low-contrast contours is equally important in the entire range of lightness. Moreover, it is necessary to compensate both the loss of sharpness and the appearance of false contours due to insignificant brightness changes, invisible in the original picture, which can increase as a result of the gradation or frequency-contrast transformations.

Since non-identical gradation transformations are inevitable in case of change in the dynamic range, first of all, let us consider their impact taking into account the possible change in the threshold of visual perception due to different conditions of consideration.

\section{Materials and methods}

Without loss of similarity, let us consider the image on the screen of the monitor to be the original, which corresponds to a certain digital file.

The image contains details of different optical density. Nearby details may differ by an arbitrary value of the optical density. Differences in color coordinates of neighboring parts will characterize the contour contrast. The contrasts calculated in this way can be greater than the threshold of visual perception, close to the threshold of visual perception or below this threshold. The observable contours are those with the contrast greater than the threshold of visual perception. 
When the dynamic range in a copy is increased, false contours may occur in the copy due to the fact that the contrasts invisible in the original exceed the threshold of visual perception, when viewing the copy. When the dynamic range is reduced, some contrasts may become smaller than the visual threshold of copy viewing and may even disappear. In the general case, regardless of changes in dynamic range both types of defects are possible.

The gradation transformation belongs to the pixel-by-pixel class, that is, it changes the value of the color coordinate of each pixel regardless of the color coordinates of the rest of the pixels in the image. For this reason, it is impossible to construct a gradation curve that would ensure the accuracy of contour information reproduction. Indeed, contour contrast depends on the color coordinates values of the neighboring parts, therefore, a different gradation transformation is required for the various spatial parts of the image, which means that at least a local transformation is required depending on the environment of the pixel being modified. One of these, commonly used for image enhancement, is the frequency-contrast transformation used to sharpen fine details. However, it is not suitable for this task, as it depends only on the frequency, not on the density content of the original. Also, the blur algorithms do not depend on the contour contrast in the sense of the difference in color coordinates between neighboring parts [4].

To solve the problem of saving contour information we can divide the image into two parts. The first part is the neighborhood of thelow-contrast contours; the second part is everything else. The first part should be reproduced exactly taking into account the threshold of visual perception when viewing the original and the copy. The second part, which does not contain low-contrast fluctuations in color coordinates, can undergo gradation transformation providing the best psychologically accurate copying.

Further, the sequence of actions is described that implements this idea based on the duplication approach to the reproduction of contour information proposed by Artyushina [5].

The sequence of actions, when performing the automated preparation of images for contour contrast reproduction control, is shown in Fig. 1. Each block reflects the stages essential for the proposed algorithm. The first stage is the transition from any color coordinates to optical densities, the logarithmic units of measure. This is necessary due to the fact that the subject of our research is the transformation of low-contrast fluctuations of neighboring parts. According to the Weber-Fechner law, in a wide range of viewing conditions the visual threshold is expressed as a constant value of the logarithm of brightness [6]. In addition, it is necessary to change the presentation format of color coordinates by switching from a quantized signal to a "continuous" one. This will help to avoid the noise of rounding.

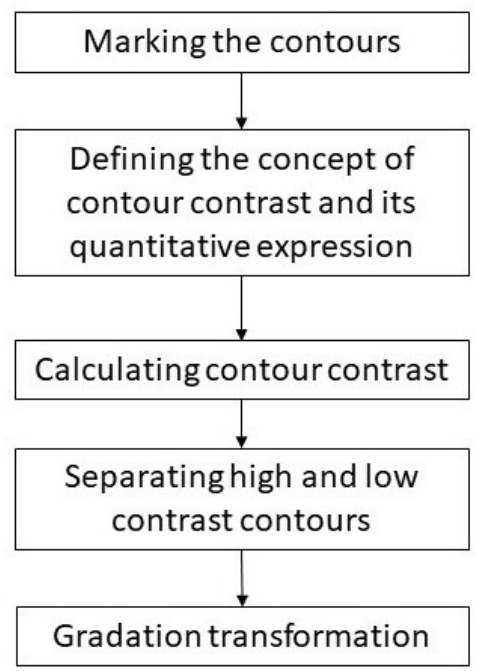

Fig. 1. Sequence of operations when performing automated preparation of images for contour contrast reproduction control

The next step is to mark the contours of the original taking into account the threshold of visual perception, when viewing the original. Any of the proven effective methods and algorithms [6] already 
implemented in MatLab environment can be used for this purpose. Next, in Fig. 2, we introduce the concept of contour contrast and its quantitative expression.

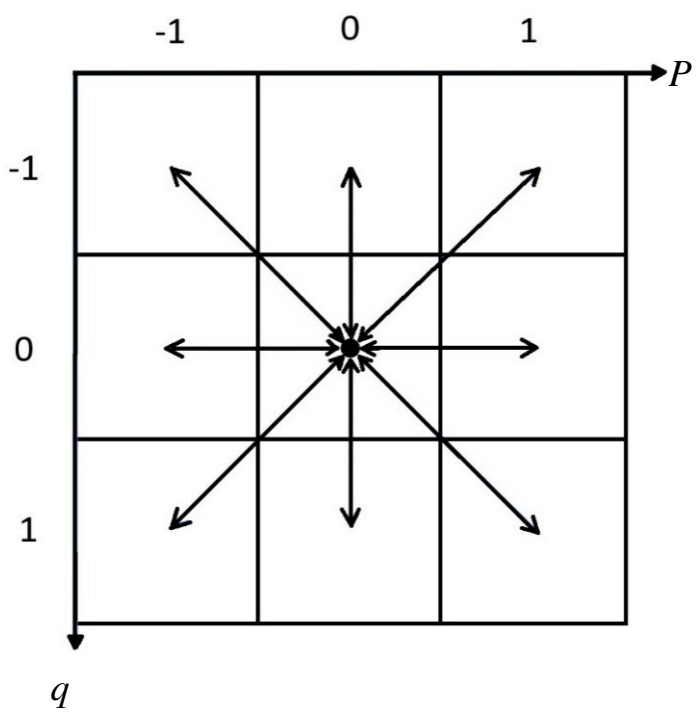

Fig. 2. Definition of contour contrast

The contour contrast is calculated using the following formula (1):

$$
\Delta K_{i j}=\max \left|D_{i j}-D_{i+p j+q}\right|,
$$

where $\Delta K_{i j}-$ contour contrast;

$D_{i j}$ - optical density value at $[i, j]$;

$D_{i}+p j+q-$ optical density value at the point;

$[i+p, j+q]-$ closest point to $[i, j]$ from the window of 3 by 3 pixels.

The contrast defined in this way quantifies the fluctuation in optical densities between the neighboring parts at each point of the contour and makes it possible to separate the contours by this value.

To divide the image into the two parts described above, the concept of the contour neighborhood is introduced, illustrated in Fig. 3.

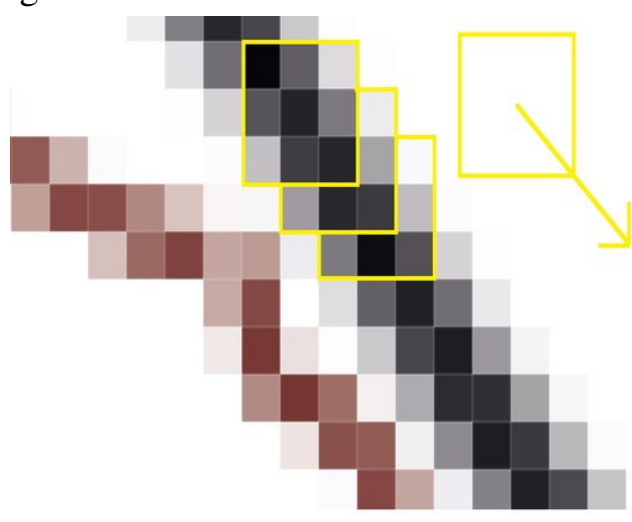

Fig. 3. Allocation scheme of contour neighborhood

In the figure it is clear thatthe contour neighborhood includes a number of pixels of nearby details. It is essential that their optical densities are defined as relative values, that is, minus the optical densities of the less dense part of the image. The contour neighborhood is found with the help of a consistent operator for object boundaries selection and a morphological operation of dilation [4].

The next operation is to split the original image into two parts. The first part contains the contour neighborhoods having a contrast that does not exceed two thresholds of visual perception. It is proposed to reproduce this part in any gradation transformations identically, if the thresholds, when 
viewing the original and the copy coincide, or linearly, ensure that the threshold of viewing the copy is the same as the threshold of viewing the original. The second part of the image is obtained by subtracting optical densities of the first part of the image (the low-contrast contour neighborhoods) from the optical densities of each pixel of the original. Thus, the second part will only contain high contrast fluctuations in optical densities between the neighboring parts. Thesefluctuationsat any gradation transformation providing psychological accuracy of reproduction will not lead to distortion of contour information. Fig. 4 illustrates different gradation transformations.
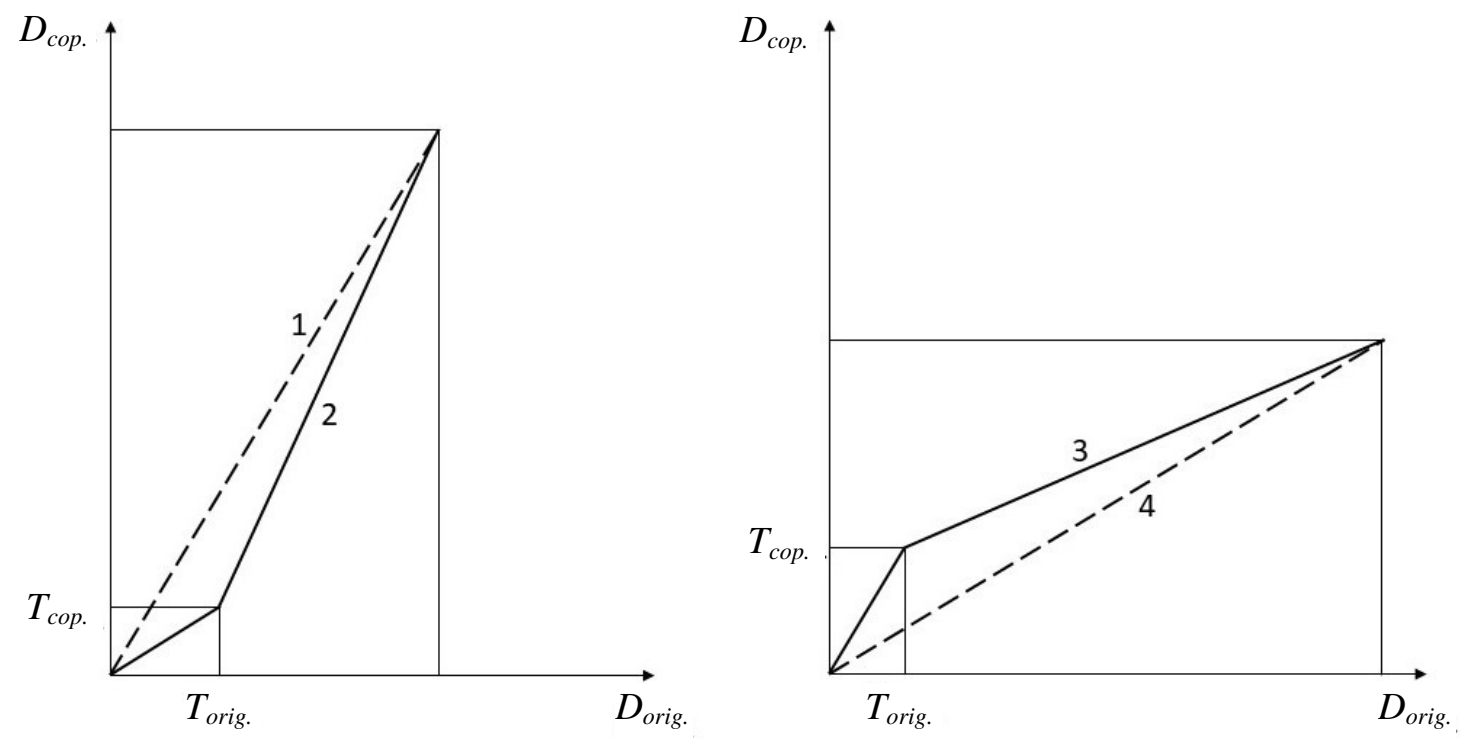

Fig 4. Performing gradation transformations by increasing and decreasing contrast of copy with respect to original: $D_{\text {orig. }}-$ optical density range of the original; $D_{c o p .}$ - optical density range of the copy; $T_{\text {orig. }}-$ threshold of perception of the original; $T_{c o p}$. - threshold of perception of the copy

After separategradation transformationsthe copy is made up of the sum of the optical densities. Thus, the contour information is saved.

Software implementation of the presented algorithm is carried out in MatLab environment. The scheme of the algorithm for determining the neighborhood of the contour is shown in Fig. 5.

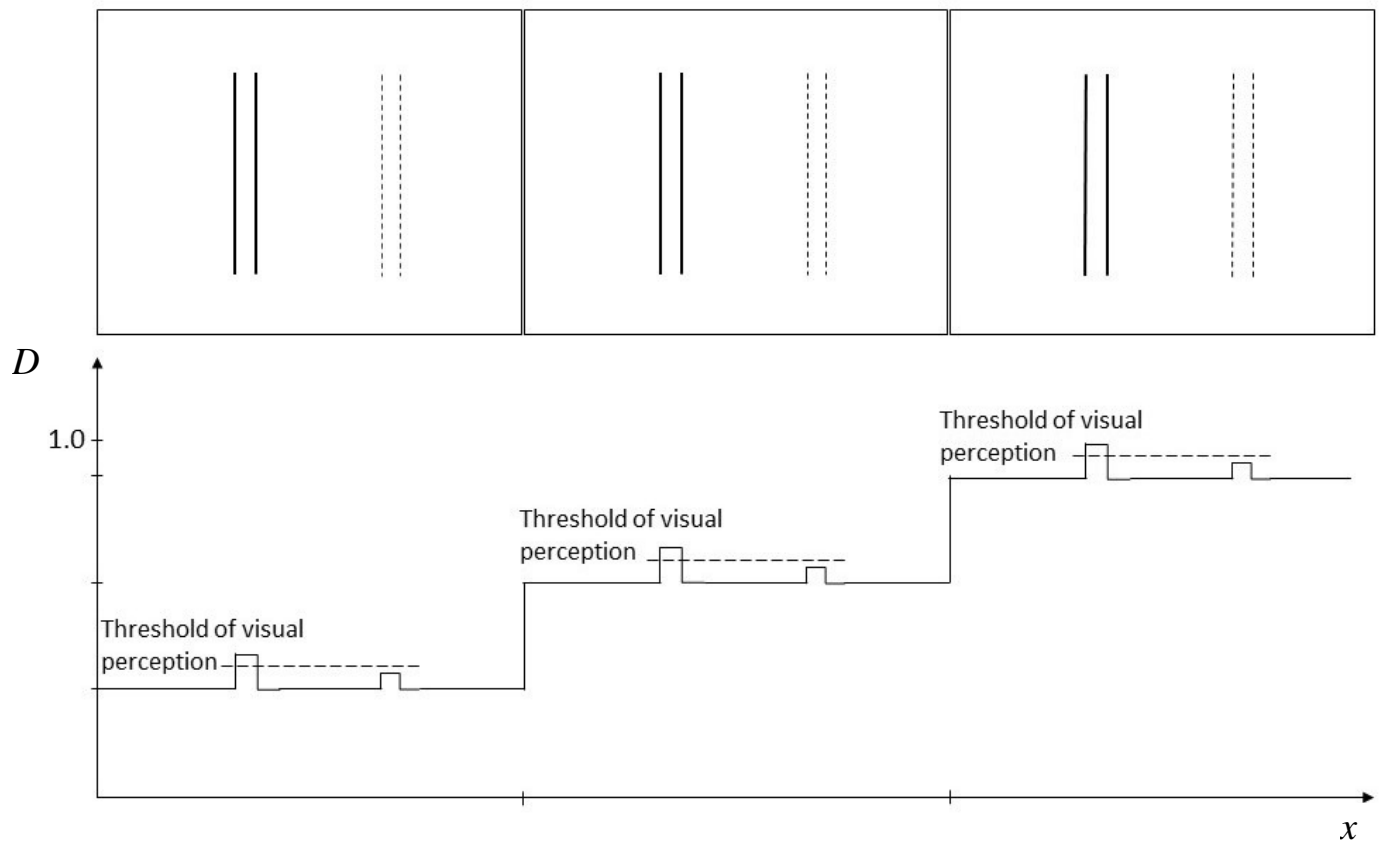

Fig. 5. Scheme of algorithm for determining contour neighborhood: $D$ - optical density; $x$ - spatial coordinate 


\section{Results and discussions}

To examine the effectiveness of the proposed algorithm a test has been designed that contains high contrast, above threshold and sub-threshold fluctuations of the optical density of the neighboring parts (Fig. 6).

a)

$$
0.6
$$

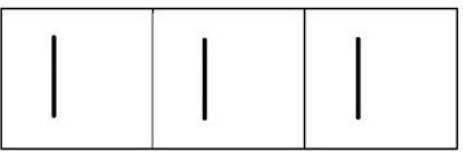

b)

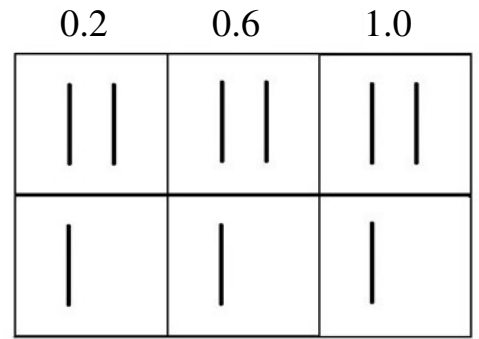

c)
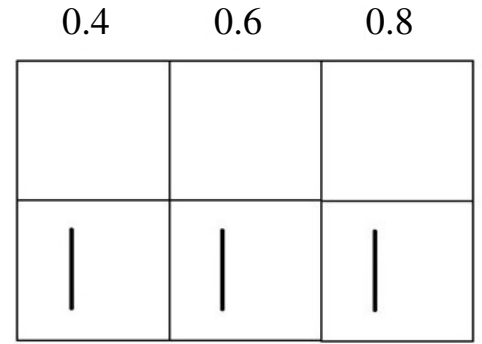

Fig 6. Test that contains high contrast, above threshold and sub-threshold fluctuations in optical density of neighboring parts: a - original image with normal dynamic range; $\mathrm{b}$ - extended dynamic range image; $\mathrm{c}$ - reduced dynamic range image

The numbers indicate the value of optical density in case of decrease or increase in contrast.

A simulation of copying the test with extended dynamic range was carried out. The simulation showed that with a uniform increase in entire image contrast on allthe three fields an additional contour is visually detected, which had a sub-threshold contrast and was invisible in the original image. When the developed algorithmis applied to the test, the required increase in the dynamic range is achieved and at the same time the contour information is saved.

The simulation of test copying with dynamic range reduction was also carried out. The simulation showed that with contrast reduction of the entire image in allthe three fields no contour is visually detected, that is, there is a loss of contour information. When the developed algorithm is applied to the test, the required reduction of the dynamic range is achieved and the contour present in the original is visually detected, that is, the contour information is saved.

\section{Conclusions}

On the basis of the introduced concept of contour contrast, an algorithm of automated image processing is proposed, which makes it possible to ensure the accuracy of contour information reproduction. The distinctive feature of the approach is the use of logarithmic units as color coordinates and the use of colorimetric metrics introduced on their basis. It is essential to determine the neighborhood of the contour. Software implementation of the algorithm is performed in the Matlab environment. Experimental testing was carried out on specially designed test objects and subject image having many small low-contrast details. The given data clearly demonstrate the effectiveness of the approach.

\section{References}

[1] Визильтер Ю. В., Желтов С. Ю. Проблемы технического зрения в современных авиационных системах // Техническое зрение в системах управления мобильными объектами 2010: Труды научно-технической конференции-семинара. Вып. 4 / Подред. Р. Р. Назирова. - М.: КДУ, 2011. - С. 11-44. (Vizilter Y.V., Zheltov S.V. Problems of computer 
vision in modern aviation systems // Computer vision in mobile objects control systems. 4th edition / edited by R.R. Nazirov. - Moscow:KDU, 2011. - pp. 11-44 ) (In Russian)

[2] Комар В.Г. Отчёт понаучно-исследовательской работе «О критерии резкости изображения в кинематографе и об оценке качества изображения в различных системах кино» // НИКФИ 1961 г.(Komar V.G.Research work report «About criteria of image acutance in cinematograph and evaluation pf image quality in different cinema systems» // NIKFI 1961) (In Russian)

[3] Артюшин Л. Ф. Основыв оспроизведения цветавфотографии киноиполиграфии // - Москва :Искусство, 1970. - 548 с. (Artyushin L.F. Color reproduction basics in photography, cinematography and polygraphy // Moscow :Iskusstvo, 1970. 548 p.) (In Russian)

[4] Шапиро Л., Стокман Дж. Компьютерное зрение пер. с англ. - 2-е изд. (эл.). - М. : БИНОМ. Лабораториязнаний, 2013. - 752 c. (Shapiro L., Stockman D. Computed vision, $2^{\text {nd }}$ edition, translation from engl. - M.:BINOM. Laboratoriyaznaniy, 2013. - 752 p.) (InRussian)

[5] Артюшина И.Л., Винокур А.И. О точности передачи градационной и структурной информации в репродукционных процессах (On the accuracy of the transmission of gradational and structural information in reproductive processes) // Сборник научных трудов Научно-исследовательского кинофотоинститута «Методы совершенствования технологии кинематографии с использованием вычислительной техники», Москва 1996г, стр. 4347.(InRussian)

[6] Кравков С.В. Пороги ощущения и их измерение // Психология ощущений и восприятия (Thresholds of sensation and their measurement // Psychology of sensations and perception.) Хрестоматия попсихологии. М., 1999. С. 242-249 (In Russian) 